\title{
Routine full blood counts as indicators of acute viral infections
}

\author{
D F NIXON, A J PARSONS, R P EGLIN \\ From the Department of Virology, Regional Public Health Laboratory, John Radcliffe Hospital, Oxford
}

SUMMARY Over a period of three weeks about 9000 full blood counts were analysed on the Technicon H6000 automated haematology machine. From these, 62 patients were identified who had abnormally high numbers of large unstained white cells; these patients were followed up for evidence of viral infection. Seventeen were either lost to follow up or in chronic renal failure; of the remaining 45 patients, 40 had viral infections, 26 of which were due to Epstein-Barr virus. In the presence of a raised number of large unstained white cells, an IgM test for Epstein-Barr virus is recommended, followed by routine serology when necessary.

When acute infection is suspected two tests are commonly requested: estimation of the erythrocyte sedimentation rate (ESR) ${ }^{1}$ and the $\mathrm{C}$-reactive protein concentration (CRP). ${ }^{2}$ The ESR may be raised in both infections and in other diseases, whereas CRP, an acute phase protein, is raised mainly in bacterial infections, though it may also rise in some connective tissue diseases and influenza type $\mathrm{A}$ infection. ${ }^{3}$ There is still a need for a rapid indicator which will distinguish between bacterial and viral infections.

Most full blood counts at this hospital are routinely analysed on the Technicon $\mathrm{H} 6000$ automated haematology machine. The $\mathrm{H} 6000$ includes a fully automated differential leucocyte analyser which examines white cells in suspension and classifies them by size and cytochemical staining, $3 \times 10^{4}$ cells being counted in a three channel continuous flow system. The first channel uses peroxidase as a stain, at a pH of $3 \cdot 2$. A combination of size and intensity of staining allows all cells except monocytes and basophils to be differentiated. The second channel uses lipases to identify monocytes at a $\mathrm{pH}$ of $6 \cdot 1$. The third channel distinguishes basophils by the staining with alcian blue at $\mathrm{pH} 2 \cdot 2$ of their heparin-containing granules.

A graphical printout of size and peroxidase staining is produced, together with absolute and relative numbers of the five white cell categories (lymphocytes, monocytes, neutrophils, basophils and eosinophils). There is an additional category of large unstained cells (LUCs)-large cells with no peroxidase activity. The normal range in our laboratory

Accepted for publication 21 January 1987 for LUCs in adults is $0 \cdot 02-0 \cdot 17 \times 10^{3} / \mathrm{ml}$, which is $0 \cdot 2-2 \cdot 3 \%$ of the total white cell count. A raised LUC score is greater than $2.3 \%$ or $0.17 \times 10^{3} / \mathrm{ml}$, or both.

An increase in LUC count on the H6000 machine occurs in various conditions including leukaemia (due to blast cells) and in infectious mononucleosis (due to an increase in atypical mononuclear cells). A raised LUC population might also be due to increased numbers of cytotoxic lymphocytes, natural killer cells, or other reactive lymphoid cells. To assess the possible diagnostic usefulness of an abnormal LUC count all cases of raised LUC scores from routine anticoagulated edetic acid blood samples were analysed over three weeks. Serum samples and clinical details were requested and the patients followed up for two months with repeat samples.

\section{Material and methods}

Samples of $2 \mathrm{ml}$ edetic acid and $10 \mathrm{ml}$ clotted blood were requested from patients through general practitioners two and six weeks after they had had raised LUC scores. The edetic acid samples were analysed on the $\mathrm{H} 6000$, and the sera from the clotted samples were tested in parallel for the presence of specific antibodies.

Complement fixation tests on paired sera from all patients were used to detect antibodies to the following organisms: influenza type $A$, influenza type $B$, adenovirus, respiratory syncytial virus (RSV), mumps virus, measles virus, herpes simplex virus (HSV), varicella zoster, cytomegalovirus (CMV), Coxsackie B, Coxiella burnetti, psittacosis, and Mycoplasma pneu- 
moniae. ${ }^{4} \mathrm{~A}$ four-fold rise in titre to a specific antigen or, if only one sample was available, a single high titre $(>128)$, was taken as evidence of infection with that organism at the time of raised LUC score.

Enzyme linked immunosorbent assays were used to detect the presence of $\operatorname{IgM}$ to hepatitis A virus, Epstein-Barr virus (EBV), rubella virus and Toxoplasma gondii. ${ }^{5}$

All patients were tested for hepatitis B surface antigen by the reverse passive haemagglutination test, ${ }^{6}$ and for antibodies to human immunodeficiency virus type-1 (HIV-1) by competitive ELISA (Wellcome). Throat swabs for virus isolation were taken in some cases.

\section{Results}

During the study, 62 patients with raised LUC scores were detected out of 9000 samples examined on the H6000. Ten patients were lost to follow up, and seven had chronic renal failure with no clinical evidence of infection, so were excluded from the study. No raised LUC scores due to blast crises in leukaemic patients were found.

Of the 62 patients, 45 remained in the study. The highest LUC score $\left(1.31 \times 10^{3} / \mathrm{ml}\right.$, equal to $11 \%$ of the total white cell count) was in a patient with EBV infection. The LUC score had returned to the normal range in all cases after two weeks. One patient with EBV infection had a raised LUC score two months after presentation, although it fell to within the normal range at the two week sample.

Of the 45 patients, 23 were monospot positive on the initial testing, and repeat samples were obtained in 11 of these. Recent EBV infection was confirmed by detection of EBV specific IgM. One patient had a positive monospot on two samples four weeks apart, but had no EBV IgM specific antibody detected on either sample; this patient had a false positive monospot, and no viral cause was found for her illness. Two more patients who initially had raised LUC scores and were EBV IgM positive but monospot negative subsequently became monospot positive, and two patients had EBV specific IgM but never gave a positive monospot reaction. Monospot positive patients had raised titres to other viruses, including adenovirus, Coxsackie $B$, influenza types $A$ and $B$, measles, mumps and RSV, presumably due to polyclonal B cell activation.

Fourteen of the 18 remaining patients showed evidence of viral infection on serology (a four-fold rise in nine, and a high titre $(>128)$ in four) or virus isolation (one patient). These comprised five influenza type A (winter period) $(n=5), C M V(n=2)$, measles $(n=3)$, mumps $(n=2)$, HSV $(n=1)$, and rubella $(n$ $=1)$. No viral diagnosis was reached for two cases. One patient had a raised LUC score due to peroxidase staining failure, and one other patient had recently undergone a cholecystectomy and had a transient rise in the LUC score. After the period of study was over another patient who had had a cholecystectomy was found to have a raised LUC count. All patients were negative for antibodies to HIV-1 and hepatitis B surface antigen.

We followed up 11 patients with septicaemias to a range of bacteria (including Staphylococcus aureus, Escherichia coli, and Pseudomonas spp.). None had raised LUC scores. Three patients with raised LUC scores after the study period were found to have malaria.

\section{Discussion}

Forty of 45 patients had raised LUC scores due to infections with a range of viruses, EBV infection being most common. Of the $26 \mathrm{EBV}$ IgM positive cases, two were monospot negative in the acute sample and two never showed positive monospots. This indicates that EBV IgM should be used as the marker of recent EBV infection instead of a single monospot test, which was negative in $10 \%$ of our patients. Morphologically, the EBV cases had large numbers of atypical mononuclear cells which contributed to the raised LUC scores.

The raised LUC scores dropped to within the normal range by two weeks after the initial sample had been taken, suggesting that this marker indicated an acute immunological response to virus infections. The

Table Findings in patients with raised LUC scores

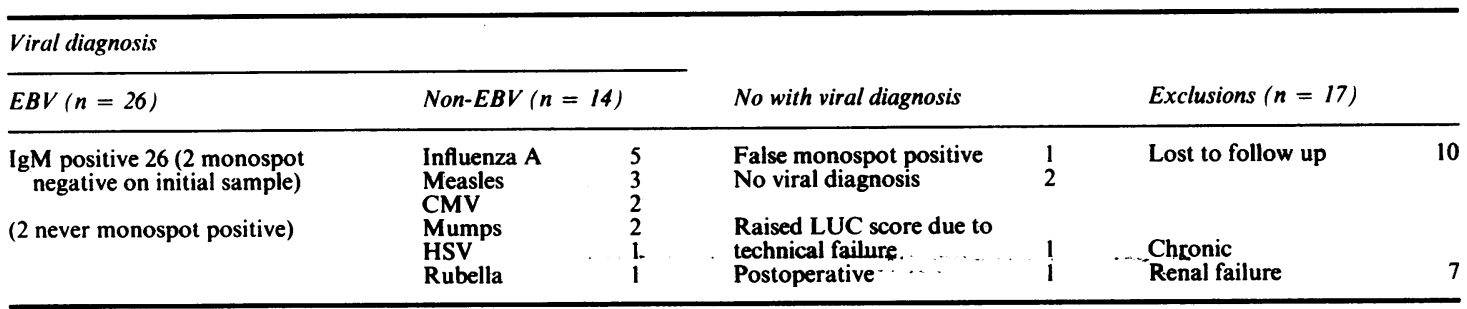


numbers of atypical cells (LUCs) fell before the lymphocytosis was corrected. Morphologically not all LUCs were atypical mononuclear cells, some being reactive immunoblasts.

A raised LUC score in a sample of acutely ill patients seems to be a marker for a range of virus infections. No additional blood sample is required, as the LUC score is obtained from a routine full blood count.

Other causes of a raised LUC score which should be excluded before a viral cause is looked for are: leukaemia; chronic renal failure; postoperative response; and malaria. A normal LUC score does not exclude viral infection as not all viruses may cause an increased LUC count.

If the clinical details suggest viral infection and the LUC score is raised we suggest an EBV IgM test, followed by routine serological screening on the initial acute and convalescent sera, if EBV infection is not detected.

We thank the general practitioners who sent repeat specimens and the staff of the haematology and virology departments for their cooperation.

\section{References}

1 Bedell SE, Bush BT. Erythrocyte sedimentation rate. Am J Med 1985;78:1001-9.

2 Pepys MB. C reactive protein fifty years on. Lancet 1981;i:653-7.

3 Cooper EH, Forbes MA, Hambling MH. Serum $\beta_{2}$-microglobulin and $C$ reactive protein concentrations in viral infections. J Clin Pathol 1984;37:1140-3.

4 Lennette EH, Schmidt NJ, eds. Diagnostic procedures for viral, rickettsial and chlamydial infections. 5th ed. Washington: American Public Health Association, 1979:24-9.

5 Supran EM. ELISA: an update. Public Health Laboratory Service Microbiology Digest 1984;1:36-44.

6 Cayzer I, Dane DS, Cameron CH, Denning JV. Rapid haemagglutination test for hepatitis B antigen. Lancet 1974;i:947-9.

Requests for reprints to: Dr DF Nixon, Department of Virology, Regional Public Health Laboratory, John Radcliffe Hospital, Oxford OX3 9DU, England. 